\title{
Phenotype of Subjects with Type 2 Diabetes May Determine Clinical Response to Chromium Supplementation
}

\author{
Zhong Q. Wang ${ }^{\star}$, Jianhua Qin ${ }^{\star}$, Julie Martin ${ }^{\star *}$, Xian H. Zhang ${ }^{\star}$, Olga Sereda*, Richard \\ Anderson, $\mathbf{P h D}^{* * *}$, Patricia Pinsonat, $\mathbf{R N}^{*}$, and William T. Cefalu, MD* \\ "Pennington Biomedical Research Center, Louisiana State University System, Baton Rouge, LA, \\ USA \\ ** University of Vermont, Burlington, Vermont USA \\ ${ }^{* * *}$ Beltsville Human Nutrition Research Center, Beltsville, MD USA
}

\begin{abstract}
Background and Aims-Considerable controversy exists regarding use of chromium $(\mathrm{Cr})$ supplementation to modulate carbohydrate metabolism in subjects with diabetes. Recently, we reported that $\mathrm{Cr}$ supplementation, provided as $1000 \mathrm{ug} /$ day as $\mathrm{Cr}$ picolinate, enhanced insulin sensitivity in subjects with Type 2 diabetes. Our data agreed with some, but not all, studies that evaluated a similar dose and formulation in Type 2 diabetes and suggested that subject selection and characteristics may be important considerations when assessing the clinical response. Thus, the goal of this study was to assess which metabolic or clinical characteristics, when obtained at baseline, best determine a clinical response to $\mathrm{Cr}$ when assessing changes in insulin sensitivity.
\end{abstract}

Methods-Seventy-three subjects with Type 2 diabetes were assessed in a double-blinded, randomized, placebo-controlled study. Subjects were assessed at baseline for glycemic control with $\mathrm{HbAlc}$ measures, oral glucose tolerance tests, and body weight and body fat measures (DEXA). After baseline, insulin sensitivity in vivo was assessed with use of hyperinsulinemiceuglycemic clamps. After the baseline clamp, subjects were randomized to receive $\mathrm{Cr}$ supplementation (1000 ug Cr/day provided as chromium picolinate) or placebo daily for 6 months. All study parameters were repeated after 6 months. The relationship of the baseline characteristics of the study subjects to the change in insulin sensitivity was determined.

Results-63\% of the subjects with Type 2 diabetes responded to the $\mathrm{Cr}$ treatment as compared to $30 \%$ with placebo. The only subject variable significantly associated with the clinical response to $\mathrm{Cr}$ was the baseline insulin sensitivity, as assessed with the hyperinsulinemic-euglycemic clamp $\left(\right.$ partial $\left.\mathrm{R}^{2}=.4038\right)(\mathrm{p}=.0004)$.

\footnotetext{
Address for correspondence: William T. Cefalu, MD, Pennington Biomedical Research Center, 6400 Perkins Road, Baton Rouge, LA 70808, Phone: 225-763-2654, Fax: 225-763-3030, E-mail: cefaluwt@pbrc.edu.

Authors and Contribution to Study:

Zhong Q. Wang: Study design, manuscript preparation

Jianhua Qin: Data analysis, manuscript review

Julie Martin: Study Coordination, subject recruitment, manuscript review

Xian H. Zhang: Study conduct, manuscript review

Olga Sereda: Study conduct, performance of clamp procedures, manuscript review

Richard Anderson: Study design, data review and analysis, manuscipt review

Patricia Pinsonat: Study coordination, subject recruitment, manuscript review

William T. Cefalu: Study design, data review and analysis, manuscript preparation

Publisher's Disclaimer: This is a PDF file of an unedited manuscript that has been accepted for publication. As a service to our customers we are providing this early version of the manuscript. The manuscript will undergo copyediting, typesetting, and review of the resulting proof before it is published in its final citable form. Please note that during the production process errors may be discovered which could affect the content, and all legal disclaimers that apply to the journal pertain.
} 
Conclusion-Subject phenotype appears to be very important when assessing the clinical response to $\mathrm{Cr}$ as baseline insulin sensitivity was found to account for nearly $40 \%$ of the variance in the clinical response to $\mathrm{Cr}$

\section{Introduction}

It is well observed in clinical trials that the measured response to an identical pharmacologic or lifestyle intervention will vary greatly among individuals. The reasons that explain a minimal as opposed to a very robust effect for subjects provided the same clinical intervention is not precisely known, but may be secondary to differences in genetic or physiologic makeup, in addition to differences in other subject characteristics. Such an observation may partially explain the considerable controversy that exists regarding use of chromium $(\mathrm{Cr})$ supplementation to modulate carbohydrate metabolism in subjects with diabetes. In part, the controversy regarding the differences reported for Cr's effect in humans stems from the lack of definitive randomized trials, the lack of "gold standard" techniques to assess glucose metabolism, the use of differing doses and formulations, and the study of heterogeneous study populations (1). We recently reported that $\mathrm{Cr}$ supplementation, provided as $1000 u g /$ day as $\mathrm{Cr}$ picolinate, enhanced insulin sensitivity in subjects with Type 2 diabetes (2). However, our data agreed with some, but not all, studies that evaluated a similar dose and formulation in subjects with Type 2 diabetes $(3,4)$. We concluded that patient selection may be an important consideration when assessing the clinical response to this nutritional supplement (2). If a specific patient phenotype is shown to be more responsive to $\mathrm{Cr}$, or alternatively, that a particular characteristic suggests that a patient is not likely to respond, such information would prove clinically invaluable. Therefore, the goal of this study was to assess which metabolic or clinical patient factors, when obtained at baseline, appear to best determine the clinical response to $\mathrm{Cr}$. In order to accomplish our goal, we assessed insulin sensitivity with use of hyperinsulinemic-euglycemic clamps before and after a specified period of $\mathrm{Cr}$ supplementation in subjects with Type 2 diabetes. We then determined which subject characteristic accounted for the greatest contribution to the change in insulin sensitivity.

\section{Research Design and Methods}

Subjects were required to have Type 2 diabetes for more than six months, an age range of $25-70$ years and a fasting glucose $\geq 125 \mathrm{mg} / \mathrm{dl}$ at time of screening. All procedures were approved and conducted in strict compliance with institutional human research guidelines.

The evaluations were double-blinded, randomized, and placebo-controlled. After entry criteria had been met, each subject met with the study nutritionist where instructions were provided for a weight maintenance diet. During the baseline period of 4 weeks, measures consisting of glycated hemoglobin, oral glucose tolerance testing (OGTT), body weight and $\%$ body fat were obtained. Forty-eight subjects had baseline measures assessed while on dietary therapy only. An additional twenty-five subjects had baseline measures assessed while on maintenance sulfonylurea therapy. Specifically, these subjects were evaluated only after a three month period during which all subjects received stable doses of glipizide gits at $5 \mathrm{mg} /$ day. Subjects are part of an ongoing double-blinded, randomized clinical trial supported by the National Institute of Health that is evaluating the effect of chromium on insulin sensitivity and assessing the specific cellular mechanism of action. No subject was studied while maintained on agents known to affect insulin sensitivity, i.e. metformin or thiazolidinediones. After completing all baseline measures, subjects were then admitted to the inpatient unit for assessment of insulin sensitivity with use of hyperinsulinemiceuglycemic clamps. After completion of the clamp procedure and assessment of baseline insulin sensitivity, subjects were randomized to receive either two 500 ug capsules of 
chromium provided as chromium picolinate (CrPic) or two placebo capsules that were identical in physical characteristics. Subjects took assigned study capsules daily for 6 months. The chromium picolinate formulation was selected for these studies based on reports that it has a higher bioavailability compared to other formulations (1). Subjects returned to clinic monthly for assessment of compliance of study medication, to receive new monthly allotment of study capsules, vital sign recording and adverse event monitoring, and to ensure that no change was occurring in dietary intake or lifestyle. All parameters, including assessment of insulin sensitivity with hyperinsulinemic, euglycemic clamps, were repeated at the end of study, i.e. 6 months after randomization. The specific methodology for the hyperinsulinemic-euglycemic clamp, DEXA scan, OGTT and glycated hemoglobin has been described (2).

Linear multiple regression was used to analyze the data on SAS. All the investigated variables were involved in the model as independent variables. Dependent variable was defined as the response to $\mathrm{Cr}$, defined as the change in insulin sensitivity (assessed with clamp studies) at end of study as compared to the baseline value. Model selection was based on $\mathrm{F}$ test.

\section{Results}

A total of 73 subjects $(38 \mathrm{M} / 35 \mathrm{~F})$ completed the protocol for which 38 were randomized to chromium. The subjects had an average ( \pm SD) age of $57.8 \pm 8.7$ years, $\mathrm{GHb}$ of $7.4 \pm 2.4 \%$, fasting glucose of $145.7 \pm 46.5 \mathrm{mg} / \mathrm{dl}$, BMI of $30.4 \pm 4.2$, body weight of $87.4+12.7 \mathrm{~kg}$, and whole body glucose disposal (by clamp) of $287 \pm 144 \mathrm{mg} / \mathrm{min}$.

The response rate (defined by an increase in insulin sensitivity from baseline clamp to end of study clamp) was $63 \%$ of the subjects randomized to $\mathrm{Cr}$ as opposed to $30 \%$ for placebo. Table 1 summarizes the contribution of the study variables to the prediction model for change in insulin sensitivity. The only subject variable significantly associated with the clinical response to $\mathrm{Cr}$ was the baseline whole-body insulin-mediated glucose disposal, i.e. insulin sensitivity, as assessed with the hyperinsulinemic clamp $(\mathrm{p}=.0004)$. This parameter accounted for nearly $40 \%$ (partial $\mathrm{R}^{2}=.4038$ ) of the variance in the clinical response to $\mathrm{Cr}$ (Table 1).

\section{Conclusions}

This preliminary report suggests that a major determinant for assessing clinical response to $\mathrm{Cr}$ in subjects with Type 2 diabetes is the presence of insulin resistance prior to intervention. As described, variables assessed in this report included demographic parameters such as age, race, and gender, metabolic parameters which included assessment of glycated hemoglobin, glucose disposal obtained during clamp, insulin and glucose response to OGTT, and phenotype parameters, as assessed by BMI, percent body fat, and body weight. With a statistical model that included all the other parameters, no other demographic or biochemical parameter other than the baseline insulin sensitivity was determined to be significant in the modeling used.

It has been well documented that concerns with past studies evaluating $\mathrm{Cr}$ have been the lack of definitive randomized trials and the lack of "gold standard" techniques to assess glucose metabolism (1). For this study, we used the most precise measure of assessing insulin action, i.e. hyperinsulinemic-euglycemic clamps. An additional strength of the study was the fact that we evaluated response in a randomized, double blinded fashion. As described, all subjects received the same lifestyle instructions and the groups consisted of being randomized to daily chromium or placebo. As observed, at end of study, the 
chromium group had a response rate of $63 \%$ whereas the response rate observed for the placebo group, i.e. $30 \%$, would not be unexpected given the study design. Due in large measure to the labor intensity of the clamp technique, the cohort of subjects reported represent the largest database of individuals with Type 2 diabetes evaluated to date with use of hyperinsulinemic clamps after a specific period of $\mathrm{Cr}$ supplementation.

The observation that baseline insulin resistance is important in predicting clinical response was also suggested in animal studies $(5,6)$. Specifically, $\mathrm{Cr}$ supplementation did not increase insulin sensitivity in lean, insulin sensitive animals whereas improved insulin action and enhanced cellular signaling were observed in obese insulin resistant rats $(5,6)$. Other studies that evaluated different formulations of chromium have also suggested improved insulin sensitivity in different animal models $(7,8)$. Thus, it would appear that in clinical states such as obesity and insulin resistance, alterations in Cr metabolism may contribute to the attenuation in insulin action which may be improved with high dose $\mathrm{Cr}$ supplementation. Such an observation, if validated, may partially explain the reported discrepancies in response to $\mathrm{Cr}$ in the human population and why $\mathrm{Cr}$ supplementation appears to have a more predictable response in hyperinsulinemic or obese states $(1,9,10)$. The precise molecular mechanism by which Cr improves insulin action in these states is the focus of the ongoing $\mathrm{NIH}$ supported clinical trial. But, it is noteworthy that the supplement had its major effect in individuals who were observed to be insulin resistant prior to the intervention. This observation, if confirmed once the study is completed, is an important public health finding given that insulin resistance was chosen as a primary endpoint because it is a key pathophysiologic feature of type 2 diabetes, obesity and the "metabolic syndrome" and is strongly associated with co-existing cardiovascular risk factors and accelerated atherosclerosis (11).

In conclusion, this study is the first to report that baseline insulin resistance is a major factor in determining whether a patient may respond on a clinical level to supplemental Cr. Insulin resistance was shown to account for approx. $40 \%$ of the variance in the insulin sensitivity response to $\mathrm{Cr}$ after the treatment period. Although the presence of insulin resistance appears to be the largest contributor to clinical response, it is important to note that over $60 \%$ of the response was not explained, which suggests that other factors, including genetic, may also play a major role.

\section{Acknowledgments}

Funding: Supported in part by R55 DK060126 and R01 DK060126 awarded to William T. Cefalu, M.D. and M01RR00109

\section{References}

1. Cefalu WT, Hu FB. Role of Chromium in Human Health and In Diabetes. Diabetes Care. 2004; 27(11):2742-51.

2. Martin J, Wang ZQ, Zhang XH, Wachtel D, Volaufova J, Matthews DE, Cefalu WT. Chromium picolinate supplementation attenuates body weight gain and increases insulin sensitivity in subjects with type 2 diabetes. Diabetes Care. 2006; 29(8):1826-32. [PubMed: 16873787]

3. Anderson RA, Cheng N, Bryden NA, Polansky MM, Cheng N, Chi J, Feng J. Elevated intakes of supplemental chromium improve glucose and insulin variables in individuals with type 2 diabetes. Diabetes. 1997; 46:1786-1791. [PubMed: 9356027]

4. Kleefstra N, Houweling ST, Jansman FGA, Groenier KH, Gans ROB, Meyboom-de Jong B, Bakker SJL, Bilo HJG. Chromium treatment has no effect in patients with poorly controlled, insulin-treated type 2 diabetes in an obese Western population: a randomized, double-blind, placebo-controlled trial. Diabetes Care. 2006; 29(3):521-5. [PubMed: 16505499] 
5. Wang ZQ, Zhang XH, Russell JC, Hulver M, Cefalu WT. Chromium picolinate enhances skeletal muscle cellular insulin signaling in vivo in obese, insulin-resistant JCR:LA-cp rats. J Nutr. 2006 Feb; 136(2):415-20. [PubMed: 16424121]

6. Cefalu WT, Wang ZQ, Zhang XH, Baldor LC, Russell JC. Oral chromium picolinate improves carbohydrate and lipid metabolism and enhances skeletal muscle Glut-4 translocation in obese, hyperinsulinemic (JCR-LA corpulent) rats. J Nutr. 2002; 132(6):1107-14. [PubMed: 12042418]

7. Clodfelder BJ, Gullick BM, Lukaski HC, Neggers Y, Vincent JB. Oral administration of the biomimetic [Cr3O $(\mathrm{O} 2 \mathrm{CCH} 2 \mathrm{CH} 3) 6(\mathrm{H} 2 \mathrm{O}) 3]+$ increases insulin sensitivity and improves blood plasma variables in healthy and type 2 diabetic rats. J Biol Inorg Chem. 2005 Mar; 10(2):119-30. Epub 2004 Dec 30. [PubMed: 15625608]

8. Shinde Urmila A, Sharma G, Xu Yan J, Dhalla Naranjan S, Goyal Ramesh K. Anti-diabetic activity and mechanism of action of chromium chloride. Exp Clin Endocrinol Diabetes. 2004 May; 112(5): 248-52. [PubMed: 15146370]

9. Wilson BE, Gondy A. Effects of chromium supplementation on fasting insulin levels and lipid parameters in healthy, non-obese young subjects. Diabetes Res Clin Pract. 1995; 28:179-184. [PubMed: 8529496]

10. Morris BW, MacNeil S, Stanley K, Gray TA, Fraser R. The inter-relationship between insulin and chromium in hyperinsulinaemic euglycaemic clamps in healthy volunteers. J Endocrinol. 1993; 139:339-345. [PubMed: 8308470]

11. Lebovitz HE. Insulin resistance--a common link between type 2 diabetes and cardiovascular disease. Diabetes Obes Metab. 2006; 8(3):237-49. [PubMed: 16634983]

\section{Abbreviations}

$\begin{array}{ll}\text { BMI } & \text { body mass index } \\ \text { CrPic } & \text { Chromium picolinate } \\ \text { DEXA scan } & \text { dual energy X-ray absorptiometry } \\ \text { GHb } & \text { glycated hemoglogin } \\ \text { OGTT } & \text { oral glucose tolerance testing }\end{array}$




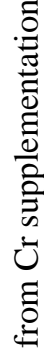
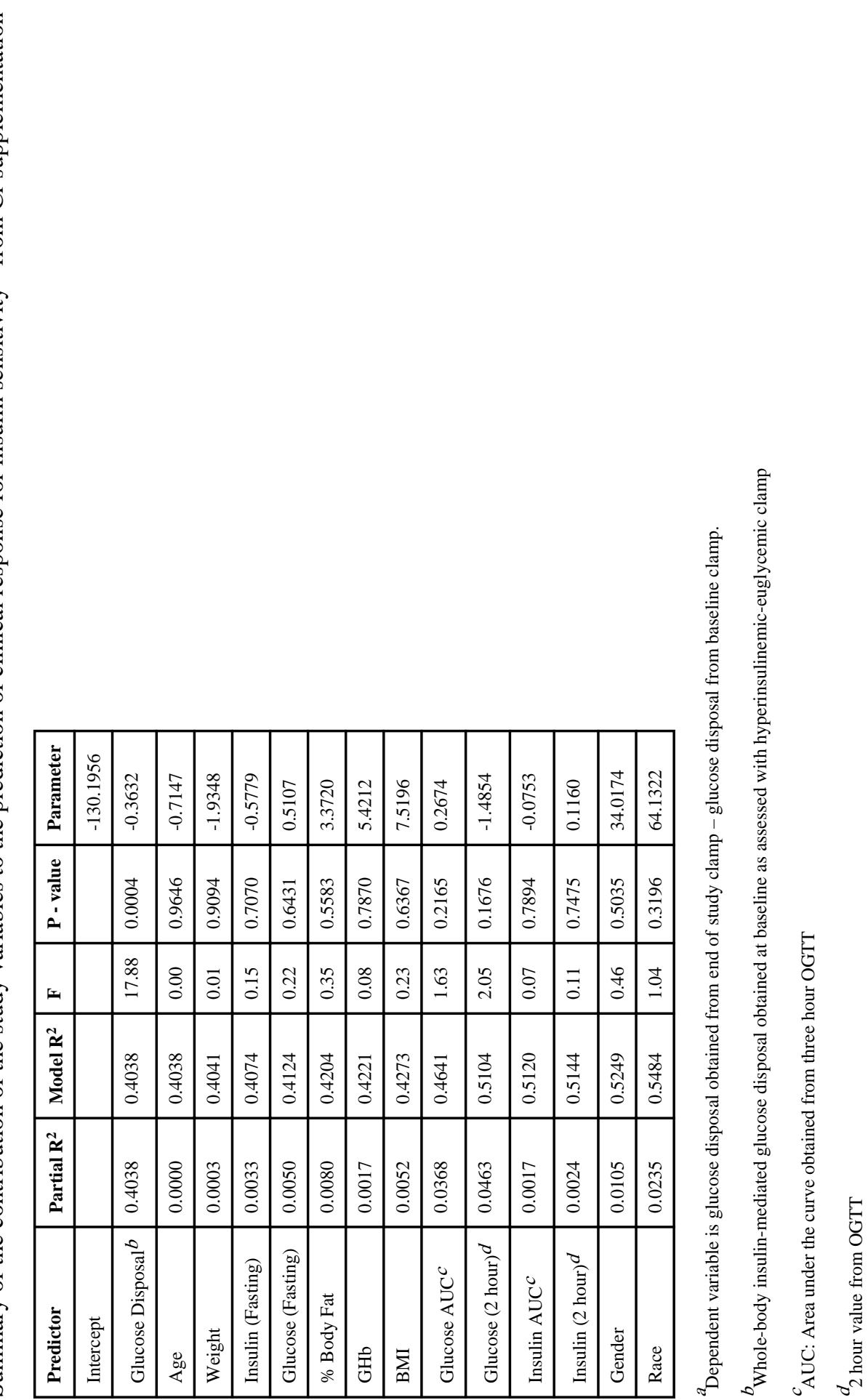